\title{
Monitoring the global-scale winter anomaly of total electron contents using GPS data
}

\author{
X. L. Huo ${ }^{1,2}$, Y. B. Yuan ${ }^{1}$, J. K. Ou ${ }^{1}$, K. F. Zhang ${ }^{2}$, and G. J. Bailey ${ }^{3}$ \\ ${ }^{1}$ Key Laboratory of Dynamic Geodesy, Institute of Geodesy and Geophysics, Chinese Academy of Sciences, Wuhan 430077, China \\ ${ }^{2}$ School of Mathematical and Geospatial Sciences, RMIT University, GPO Box 2476V, Melbourne, Australia \\ ${ }^{3}$ Applied Mathematics Section, School of Mathematics and Statistics, University of Sheffield, Hicks Building, Sheffield S3 7HR, U.K.
}

(Received June 14, 2008; Revised May 6, 2009; Accepted May 20, 2009; Online published October 19, 2009)

\begin{abstract}
The winter anomaly phenomenon of Total Electron Contents (TEC) at latitudes $15^{\circ}-60^{\circ} \mathrm{N}$ and $15^{\circ} \mathrm{S}-60^{\circ} \mathrm{S}$ is presented using GPS carrier-phase data obtained from GPS stations during 2002. The correlation between the $\left[\mathrm{O} / \mathrm{N}_{2}\right]$ ratio estimated using the NRLMSISE-00 atmospheric model and the TEC winter anomaly is also investigated. The numerical results show that the TEC winter anomaly in different regions of the world tends to be dominated by different factors. In North America, the TEC winter anomaly is strongly affected by the magnetospheric processes in high latitudes and the $\left[\mathrm{O} / \mathrm{N}_{2}\right]$ ratio. In the Euro-Africa and Russia-Asia regions, the TEC winter anomaly depends mainly on the $\left[\mathrm{O} / \mathrm{N}_{2}\right]$ ratio at the latitude band of $30^{\circ}-60^{\circ} \mathrm{N}$, and the extent of the TEC winter anomaly gradually decreases from $60^{\circ} \mathrm{N}$ to $30^{\circ} \mathrm{N}$. The extent of the TEC winter anomaly increases at the latitude band of $15^{\circ}-30^{\circ} \mathrm{N}$ due to the influence of the meridional neutral wind and the seasonal changes of the subsolar point. However, the TEC winter anomaly was not observed in southern hemisphere in 2002. The TEC equinoctial asymmetries in the northern and southern hemisphere are also presented using GPS TEC values collected in March and September 2002.
\end{abstract}

Key words: Total Electron Content (TEC), winter anomaly, Global Positioning System (GPS).

\section{Introduction}

The winter or seasonal anomaly phenomenon can be said to exist if the daytime peak electron density $\left(N_{\mathrm{m}} F_{2}\right)$ in winter is greater than that in summer. Rishbeth (1998) focused mainly on the winter anomaly or seasonal anomaly of the $F_{2}$-layer. The earliest explanation of winter anomaly was attributed to the temperature change (e.g., Appleton, 1935). Rishbeth and Setty (1961) suggested that the seasonal anomaly was caused by changes in chemical composition, specifically the $\left[\mathrm{O} / \mathrm{N}_{2}\right]$ ratio. One of the most commonly accepted theory today is that the chemical composition changes caused by a global circulation in the thermosphere accounts for the anomaly in noon $N_{\mathrm{m}} F_{2}$ (e.g., King, 1964; Ducan, 1969; Torr and Torr, 1973; Millward et al., 1996; Rishbeth, 1998; Rishbeth et al., 2000). However, other factors of seasonal change in the ionosphere have also been put forward, such as the daytime meridional wind and the seasonal changes of the subsolar point. At solstice, the meridional neutral wind modulates the equatorial plasma fountain with a general interhemispheric flow from the summer to the winter hemisphere. This wind also affects the equatorial ionospheric anomaly (EIA) diffusion of ionization from the magnetic equator down the magnetic field lines towards the equatorial anomaly crests (Bailey et al., 1982; Balan et al., 1995, 1997a; Balan and Bailey, 1996), while the seasonal location of the subsolar point in rela-

Copyright (c) The Society of Geomagnetism and Earth, Planetary and Space Sciences (SGEPSS); The Seismological Society of Japan; The Volcanological Society of Japan; The Geodetic Society of Japan; The Japanese Society for Planetary Sciences; TERRAPUB. tion to the magnetic equator will increase or decrease the local ionization production rate (Walk et al., 1994; Tsai et al., 2001). Based on this scenario, seasonal effects on the crests should be expected, with the crest maximum in winter and its minimum in summer. Some researchers have also shown that the ionospheric $F_{2}$-layer seasonal and solar cycle variations may be influenced by changes in photochemical conditions, such as, by $\mathrm{O}^{+}$ions in metastable states and by the vibrational excitation of $\mathrm{N}_{2}$, both of which modify the value of the ion's loss rate (Richards and Torr, 1986; Jenkins et al., 1991; Ennis et al., 1995; Pavlov and Pavlova, 2005). However, the well-known seasonal anomaly of electron density disappears at altitudes above about $400 \mathrm{~km}$, based on observations with the MU radar and SUPIM model (Balan et al., 1997b; Balan and Otsuka, 1998; Kawamura et al., 2002) and the Hinotori satellite (Su et al., 1998).

Since the development of satellite beacon techniques, the leading ionospheric parameter, which is total electron content (TEC) from the dual-frequency signals of Global Positioning System (GPS), has been used to monitor the temporal and spatial behaviors of the ionosphere (e.g. Mannucci et al., 1998; Schaer, 1999; Yuan and Ou, 2003; Huo et al., 2005; Jin and Park, 2007; Kotake et al., 2007; Lin et al., 2007). TEC is measured in total electron content units (TECU; 1 TECU $=10^{16}$ electrons $/ \mathrm{m}^{2}$ ).

In this paper, the global-scale winter anomaly of ionospheric TEC is discussed using GPS carrier-phase data collected in 2002 from the GPS stations of the International GNSS Service (IGS) and Crustal Movement Observation Network of China (CMONOC). The equinoctial asymme- 


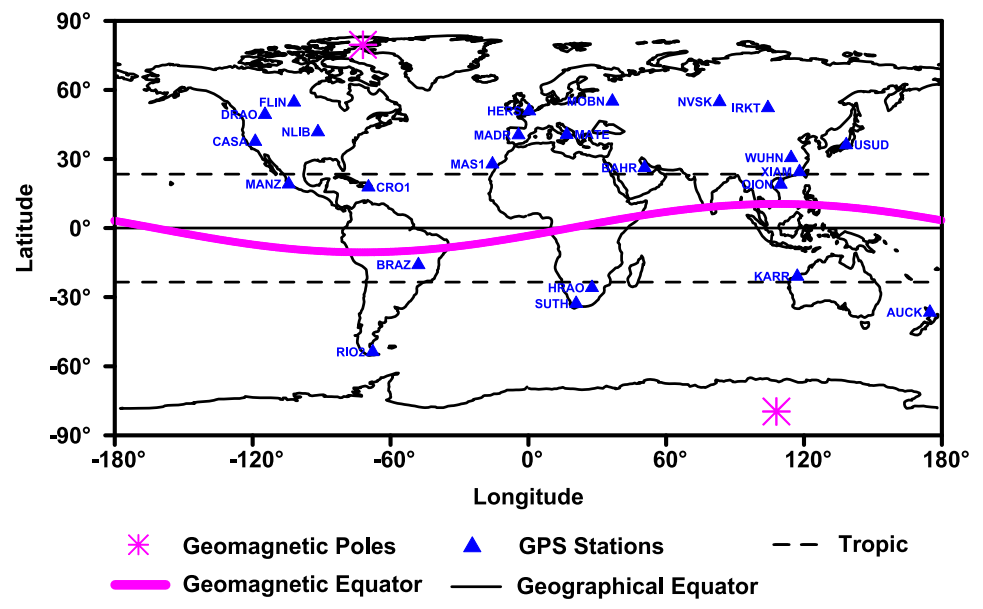

Fig. 1. The geographical location of GPS stations used for this research.

try of TEC in the ionosphere is also presented, with stronger TEC values in March than in September. In particular, there are two important points that require consideration. First, the seasonal differences are minimal in the equatorial regions (between geographical latitude $15^{\circ} \mathrm{N}$ and $15^{\circ} \mathrm{S}$ ), and the variations of TEC are also greatly influenced by the geomagnetic activities in the near-pole regions (greater than geographical latitude $60^{\circ} \mathrm{N}$ and $60^{\circ} \mathrm{S}$ ). Therefore, these latitude bands are disregarded in our study. Second, in the northern hemisphere, we group the year into four summer months (May-August), four winter months (NovemberFebruary), two spring months (March and April), and two autumn months (September and October); in the southern hemisphere, the year is classified into four seasons: four summer months (November-February), four winter months (May-August), two spring months (September and October), and two autumn months (March and April). It should also be noted that solar activity in 2002 was at high levels with $F_{10.7}$ flux values of between 113 and 261 and that GPS data with magnetic activity index $D_{\text {st }} \leq-75$ are not considered.

\section{Data and Results}

To investigate the TEC winter anomaly in different latitude regions of the world, we first consider the geographical location of the selected GPS stations. Figure 1 shows the location of the GPS stations. In this paper, the research regions of interest are divided into three latitude bands in the northern hemisphere, including $60^{\circ}-45^{\circ} \mathrm{N}, 45^{\circ}-30^{\circ} \mathrm{N}$, and $30^{\circ}-15^{\circ} \mathrm{N}$. Two GPS stations for each latitude band in different continents are employed, respectively, to investigate the variations in ionospheric TEC. Only two GPS stations in different continents are selected in the southern hemisphere due to the scarcity of the GPS networks.

\subsection{GPS TEC}

The diurnal TEC variations over each GPS station are estimated in a solar-geomagnetic reference frame using a loworder spherical harmonic function and the high-precision dual-frequency GPS carrier-phase data of 2002. The systematic TEC errors, namely hardware biases in the satellites and receivers, are lumped together with the carrier-phase ambiguities and are determined together with the TEC pa- rameters using the least square fitting method that has been discussed in detail by Yuan et al. (2007). The daily mean value of TEC data between 0830 hours local time and 1630 hours local time is assumed to be the daytime value of TEC $\left(\mathrm{TEC}_{\mathrm{d}}\right) . \mathrm{TEC}_{\mathrm{s}}$ denotes the mean value of all $\mathrm{TEC}_{\mathrm{d}}$ in summer, and $\mathrm{TEC}_{\mathrm{w}}$ denotes the mean value of all $\mathrm{TEC}_{\mathrm{d}}$ in winter. The extent of the TEC winter anomaly in different regions of the world is depicted using the differences between $\mathrm{TEC}_{\mathrm{s}}$ and $\mathrm{TEC}_{\mathrm{w}}$ (i.e. $\mathrm{TEC}_{\mathrm{w}}-\mathrm{TEC}_{\mathrm{s}}$ ) (see the left panel of Fig. 2). In addition, the mean values of $\mathrm{TEC}_{\mathrm{d}}$ during the periods 19-23 March and 21-25 September in 2002 have also been used to reveal the existence of equinoctial asymmetries in the ionosphere over different GPS stations (see Fig. 3).

\subsection{The $\left[\mathrm{O} / \mathrm{N}_{2}\right]$ ratio}

The NRLMSISE-00 empirical atmosphere model was obtained from NASA's Goddard Space Flight Centre (GSFC) and is used to estimate the $\left[\mathrm{O} / \mathrm{N}_{2}\right]$ ratio (Picone $e t$ al., 2002). In this study, the daily mean value of the $\left[\mathrm{O} / \mathrm{N}_{2}\right]$ ratio between 0830 hours local time and 1630 hours local time is assumed to be the daytime $\left[\mathrm{O} / \mathrm{N}_{2}\right]$ ratio $\left(\mathrm{RON}_{\mathrm{d}}\right)$ above each GPS station. $\mathrm{RON}_{\mathrm{s}}$ denotes the mean value of all $\mathrm{RON}_{\mathrm{d}}$ in the summer, and $\mathrm{RON}_{\mathrm{w}}$ denotes the mean value of all $\mathrm{RON}_{\mathrm{d}}$ in the winter. Using the differences between the summer and winter daytime $\left[\mathrm{O} / \mathrm{N}_{2}\right]$ ratio $\left(\mathrm{RON}_{\mathrm{w}}-\mathrm{RON}_{\mathrm{s}}\right)$ and the related TEC values, the winter anomaly in the ionosphere is discussed using quantitative analyses (see Fig. 2). The mean values of $\mathrm{RON}_{\mathrm{d}}$ during the periods 19-23 March and 21-25 September in 2002 over different GPS stations are also employed to display the equinoctial asymmetries in the thermosphere (see Fig. 3).

\subsection{Results}

The differences for the TEC values and $\left[\mathrm{O} / \mathrm{N}_{2}\right]$ ratio between the summer and winter over different GPS stations are illustrated in Fig. 2 as a first step in investigating the correlation between the TEC winter anomaly and the $\left[\mathrm{O} / \mathrm{N}_{2}\right]$ ratio. In Fig. 2, the horizontal axis represents different GPS stations, and the left vertical axes in the left and right panels are the differences in TEC between the summer and winter $\left(\mathrm{TEC}_{\mathrm{W}}-\mathrm{TEC}_{\mathrm{s}}\right)$ and the differences in the $\left[\mathrm{O} / \mathrm{N}_{2}\right]$ ratio between summer and winter $\left(\mathrm{RON}_{\mathrm{w}}-\mathrm{RON}_{\mathrm{s}}\right)$ respectively.

According to Fig. 2, the extent of the winter anomaly 

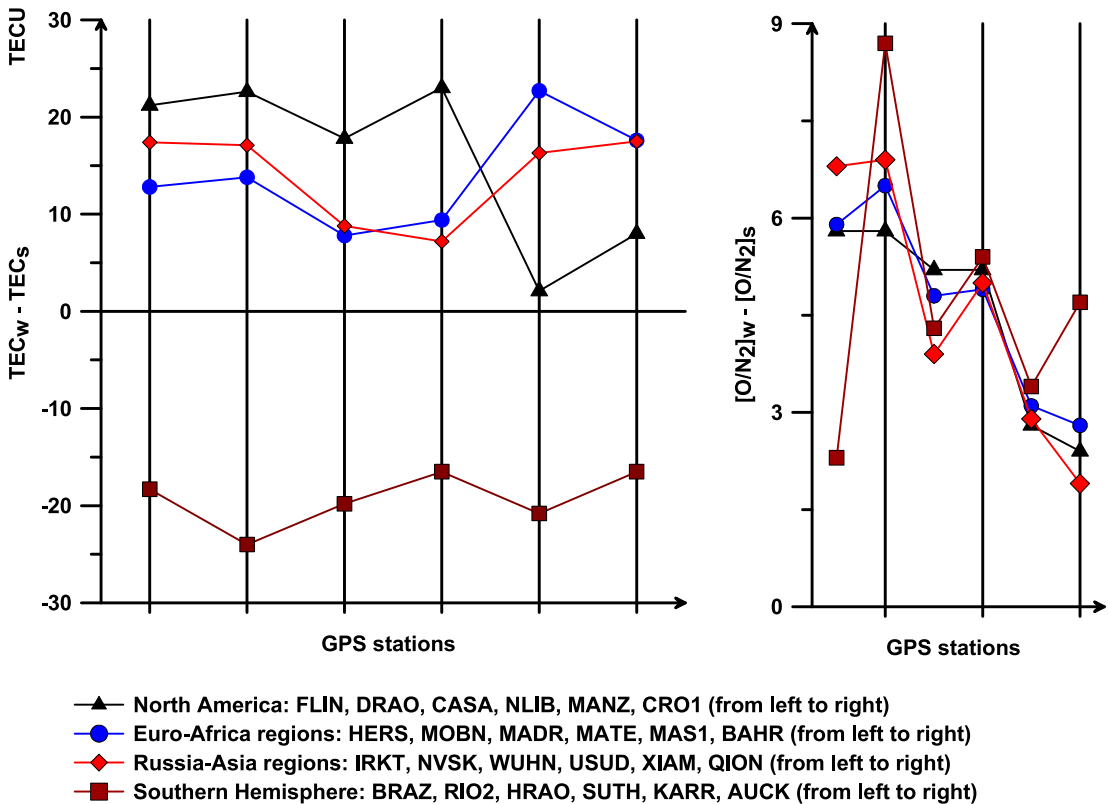

Fig. 2. The difference of TEC and $\left[\mathrm{O} / \mathrm{N}_{2}\right]$ ratio between summer and winter in different GPS stations in 2002.
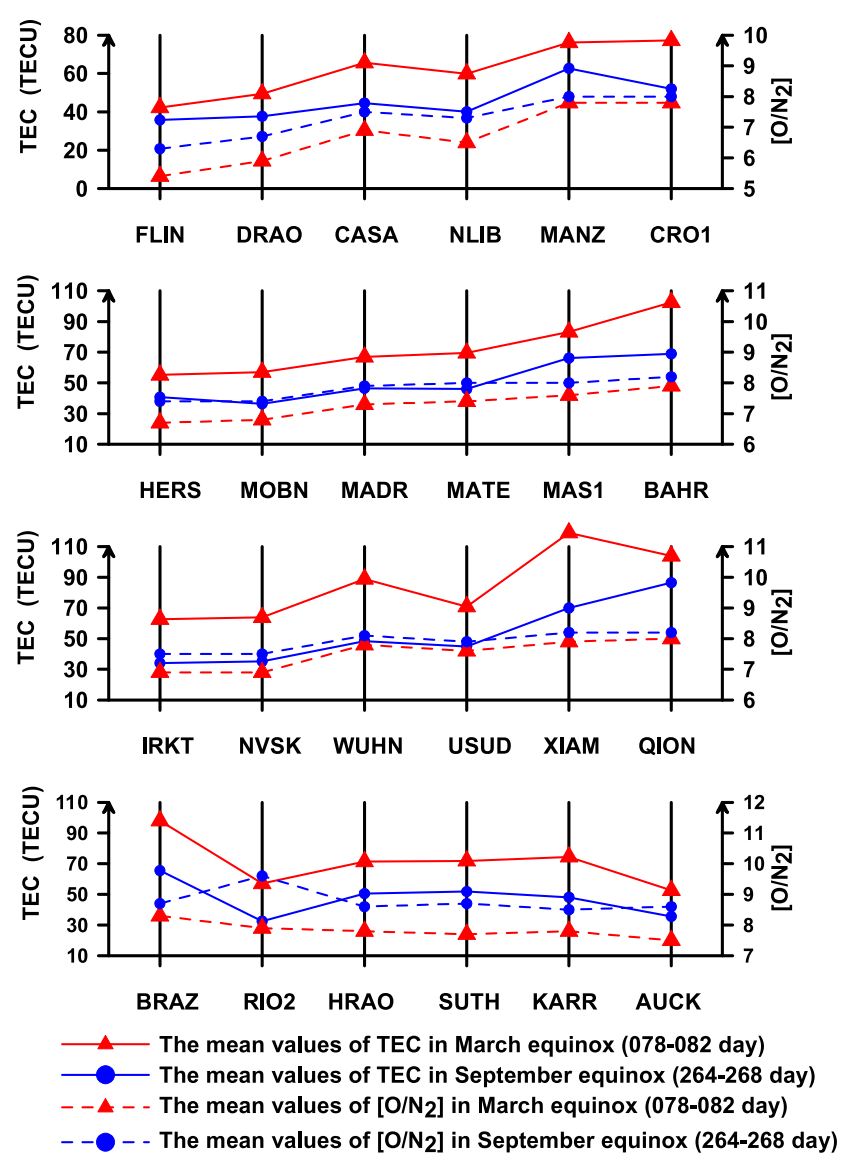

Fig. 3. The mean values of TEC and $\left[\mathrm{O} / \mathrm{N}_{2}\right]$ in March and September in different GPS stations in 2002.

over different regions of the world is as follows. In North America, the TEC winter anomaly is evident at the latitude band between $30^{\circ} \mathrm{N}$ and $60^{\circ} \mathrm{N}$ (FLIN, DRAO, CASA, and NLIB), with TEC values during winter being about 20 TECU higher than those during the summer. How- ever, the extent of the winter anomaly is lowest at the latitude band of $15^{\circ}-30^{\circ} \mathrm{N}$ (MANZ and CRO1). In the EuroAfrica and Russia-Asia regions, the extent of the winter anomaly at different latitude bands varies. The TEC winter anomaly is obvious at the latitude bands of $45^{\circ}-$ $60^{\circ} \mathrm{N}$ (HERS, MOBN, IRKT, and NVSK) and $15^{\circ}-30^{\circ} \mathrm{N}$ (MAS1, BAHR, XIAM, and QION), while the TEC difference between summer and winter at the latitude band of $30^{\circ}-45^{\circ} \mathrm{N}$ is less than 10 TECU (MADR, MATE, WUHN, and USUD). It is also worth noting that the extent of the TEC winter anomaly at the latitude band of $45^{\circ}-60^{\circ} \mathrm{N}$ is lower in the Euro-Africa regions (HERS and MOBN) than in the Russia-Asia regions (IRKT and NVSK). From Fig. 2, it can also be seen that the TEC winter anomaly is not observed in southern hemisphere (BRAZ, RIO2, HRAO, SUTH, KARR, and AUCK). Figure 2 also shows that the differences in the daytime $\left[\mathrm{O} / \mathrm{N}_{2}\right]$ ratio between summer and winter $\left(\mathrm{RON}_{\mathrm{w}}-\mathrm{RON}_{\mathrm{s}}\right)$ have a tendency to decrease from $60^{\circ} \mathrm{N}$ to $15^{\circ} \mathrm{N}$. The differences in the $\left[\mathrm{O} / \mathrm{N}_{2}\right]$ ratio are high at the latitude band of $45^{\circ}-60^{\circ} \mathrm{N}$, and the differences are less at the latitude band of $15^{\circ}-30^{\circ} \mathrm{N}$. It needs to be pointed out that the associated differences of the $\left[\mathrm{O} / \mathrm{N}_{2}\right]$ ratio at the latitude band $45^{\circ}-60^{\circ} \mathrm{N}$ are larger in the Russia-Asia regions (IRKT and NVSK) than those in Europe (HERS and MOBS) and North America (FLIB and DRAO). In the southern hemisphere, the $\left[\mathrm{O} / \mathrm{N}_{2}\right]$ ratio during the winter is higher than that during summer.

To summarize, the results from the Euro-Africa and Russia-Asia regions at the latitude band of $30^{\circ}-60^{\circ} \mathrm{N}$ indicate that the extent of the ionospheric TEC winter anomaly is consistent with the variations in the $\left[\mathrm{O} / \mathrm{N}_{2}\right]$ ratio between the summer and winter. However, in North America, although the changes in the $\left[\mathrm{O} / \mathrm{N}_{2}\right]$ ratio between the summer and winter at the latitude band of $45^{\circ}-60^{\circ} \mathrm{N}$ differ from those at $30^{\circ}-45^{\circ} \mathrm{N}$, the extent of the TEC winter anomaly is similar. In addition, the changes in the $\left[\mathrm{O} / \mathrm{N}_{2}\right]$ ratio in North America are not significant, but the TEC winter 
anomaly is indeed the strongest. Therefore, it can be concluded that there are other factors affecting the TEC winter anomaly in this region besides the $\left[\mathrm{O} / \mathrm{N}_{2}\right]$ ratio in North America. At latitude $15-30^{\circ} \mathrm{N}$, the extent of the TEC winter anomaly is weaker, in association with the changes of the $\left[\mathrm{O} / \mathrm{N}_{2}\right]$ ratio in North America, but the extent of the TEC winter anomaly is stronger for the same latitude band in the Euro-Africa and Asia regions. This indicates that the TEC winter anomaly is also strongly influenced by other factors for the latitude band $15-30^{\circ} \mathrm{N}$ in the Euro-Africa and Asia regions. In the southern hemisphere, the TEC winter anomaly is not observed, although the $\left[\mathrm{O} / \mathrm{N}_{2}\right]$ ratio during the winter is higher than that during summer.

Figure 3 shows the mean TEC values and the mean $\left[\mathrm{O} / \mathrm{N}_{2}\right]$ ratio in March and September over all selected GPS stations. In Fig. 3, the horizontal axis denotes different GPS stations, and the left and right vertical axes denote the TEC values and the $\left[\mathrm{O} / \mathrm{N}_{2}\right]$ ratio, respectively. From Fig. 3, it is clear that TEC values over all selected GPS stations in March are larger than those in September, while the $\left[\mathrm{O} / \mathrm{N}_{2}\right]$ ratios in March are lower than those in September.

\section{Discussion}

Using the CTIP model, Millward et al. (1996) investigated the seasonal and semiannual variations in peak noontime electron density. They suggested that the $\left[\mathrm{O} / \mathrm{N}_{2}\right]$ ratio is enhanced in the winter hemisphere by the global thermospheric circulation, and the $\left[\mathrm{O} / \mathrm{N}_{2}\right]$ ratio changes lead to the changes in the production/loss rate of electrons. According to this theory, the TEC winter anomaly at the latitude band $30^{\circ}-60^{\circ} \mathrm{N}$ can be interpreted appropriately in the Euro-Africa and Russia-Asia regions. In Fig. 2, due to the changes in the $\left[\mathrm{O} / \mathrm{N}_{2}\right]$ ratio between summer and winter, the extent of the TEC winter anomaly in the Euro-Africa and Russia-Asia regions is larger at latitude band $45^{\circ}-60^{\circ} \mathrm{N}$ than that at latitude band $30^{\circ}-45^{\circ} \mathrm{N}$. The extent of the TEC winter anomaly at latitude band $45^{\circ}-60^{\circ} \mathrm{N}$ is larger in the Russia-Asia region than that in the Euro-Africa regions. At latitude band $30^{\circ}-45^{\circ} \mathrm{N}$, the extent of the winter anomaly is similar in the Euro-Africa and Russia-Asia regions because of the similarity of the $\left[\mathrm{O} / \mathrm{N}_{2}\right]$ ratio changes between the summer and winter.

In North America, the differences in the $\left[\mathrm{O} / \mathrm{N}_{2}\right]$ ratio between the summer and winter are not significant, but the extent of the TEC winter anomaly is the strongest. Unlike the Euro-Africa and Russia-Asia regions in the vicinity of 'farfrom-geomagnetic-pole' sector, TEC variations over North America are closely related to the magnetospheric processes (Rishbeth, 1998). The theory proposed by Millward et al. (1996) is that magnetospheric processes deposit large amounts of energy into the thermosphere by joule heating and particle precipitation and then drive a local equatorward wind in the equatorward side of the auroral region. Other researchers have also suggested that the ionospheric effects of the soft electron precipitation cause the increases in the electron concentration found in the $F_{2}$-region (e.g. Shepherd, 1979; Namgaladze et al., 1997). At the same time, this effect of magnetospheric processes is affected intensively by the poleward wind produced by solar heating, which extends to relatively low geographic latitudes in the 'near-magnetic-pole' sectors of North America (Rishbeth, 1998). Furthermore, taking the variations of solar zenith angle and $\left[\mathrm{O} / \mathrm{N}_{2}\right]$ ratio into account, it can be concluded that the magnetospheric processes in the high latitudes will produce the charged particles and that these charged particles will diffuse down to the middle latitudes due to the role of the equatorward wind. Therefore, the combination of the $\left[\mathrm{O} / \mathrm{N}_{2}\right]$ ratio and the magnetospheric processes lead to the stronger winter anomaly in North America, and this influence also extends down to latitude band $30^{\circ}-60^{\circ} \mathrm{N}$. Accordingly, in North America, the extent of the TEC winter anomaly at latitude band $30^{\circ}-45^{\circ} \mathrm{N}$ is similar to that at latitude band $45^{\circ}-60^{\circ} \mathrm{N}$.

It should be noted that the extent of the TEC winter anomaly at latitude band $15^{\circ}-30^{\circ} \mathrm{N}$ is less in North America than in the Euro-Africa and Russia-Asia regions (see the left panel of Fig. 2). However, the differences in the $\left[\mathrm{O} / \mathrm{N}_{2}\right]$ ratio between the summer and winter are similar in those regions (see the right panel of Fig. 2). It has been suggested that the meridional neutral winds modulate the equatorial ionospheric fountain differently at different altitudes and latitudes, with a general interhemispheric flow from the summer to the winter hemisphere at altitudes above the $F$-region peaks at solstice. The daytime meridional winds then affect the Equatorial Ionospheric Anomaly (EIA) diffusion of ionization from the magnetic equator down to the magnetic field lines towards the crests, with a larger plasma flow towards the winter hemisphere with stronger poleward winds (Balan et al., 1995, 1997; Balan and Bailey, 1996). Walk et al. (1994) and Tsai et al. (2001) investigated the seasonal variations in the ionospheric TEC in the two equatorial anomaly regions and explained this variation by the seasonal location of the subsolar point in relation to the geomagnetic equator, which increases or decreases the loss rates of ionizations. In detail, during summer in the northern hemisphere, the subsolar point is near the tropic of cancer (see Fig. 1). Small TEC values in the summer occur at the latitude band $15^{\circ}-30^{\circ} \mathrm{N}$ since ionospheric ions and electrons significantly combine together within the subsolar regions. However, during winter in the northern hemisphere, large TEC values appear near the geomagnetic equator due to the stronger poleward winds. From Fig. 1, it is clear that the geographical latitude band $15^{\circ}-30^{\circ}$ in the Euro-Africa and Russia-Asia regions is close to the crest of the geomagnetic equator and that the geographical latitude band $15^{\circ}-30^{\circ} \mathrm{N}$ in North America is too far from the crest of the geomagnetic equator. Therefore, the differences in TEC between summer and winter for the latitude band $15^{\circ}-30^{\circ}$ are larger in the Euro-Africa and Russia-Asia regions than in North America. That is, a stronger winter anomaly of TEC appears in the Euro-Africa and Russia-Asia regions for the latitude band $15^{\circ}-30^{\circ}$.

However, in Fig. 2, TEC values in the southern hemisphere are higher in the summer than in the winter, although the values of the $\left[\mathrm{O} / \mathrm{N}_{2}\right]$ ratio in the southern hemisphere are higher in the winter than in the summer. The TEC winter anomaly was not observed in the southern hemisphere in 2002, and this needs to be further investigated in the future.

As discussed in Section 2.3, the equinoctial asymmetries in the ionosphere and thermosphere, which are similar in 
the northern and southern hemisphere, have been confirmed using TEC from GPS data and the $\left[\mathrm{O} / \mathrm{N}_{2}\right]$ ratio from the NRLMSISE-00 model. The daytime TEC values are larger in March than that in September, but the $\left[\mathrm{O} / \mathrm{N}_{2}\right]$ ratio is larger in September than in March. Our results further confirm that the equinoctial asymmetries in the ionosphere arise mainly from neutral winds and that composition makes only a minor contribution (Balan et al., 1997b; Balan and Otsuka, 1998; Kawamura et al., 2002).

\section{Conclusions}

The correlation between the daytime TEC and the $\left[\mathrm{O} / \mathrm{N}_{2}\right]$ ratio has been studied using GPS carrier-phase data and the NRLMSISE-00 atmosphere model. Additionally, the equinoctial asymmetry in ionospheric TEC is also presented using GPS TEC data collected in 2002.

Our numerical results show that the TEC winter anomaly in North America is strongly influenced by the magnetospheric processes in the mid- to high-latitude areas and by the $\left[\mathrm{O} / \mathrm{N}_{2}\right]$ ratio. The strongest TEC winter anomaly is evident at latitude band $30^{\circ}-60^{\circ} \mathrm{N}$. However, the winter anomaly is weak at latitude band $15^{\circ}-30^{\circ} \mathrm{N}$. In the EuroAfrica and Russia-Asia regions, the TEC winter anomaly mainly depends on changes in the $\left[\mathrm{O} / \mathrm{N}_{2}\right]$ ratio at the mid- to high-latitude regions, and the extent of TEC winter anomaly gradually decreases from $60^{\circ} \mathrm{N}$ to $30^{\circ} \mathrm{N}$. The TEC winter anomaly at latitude band $45^{\circ}-60^{\circ} \mathrm{N}$ is stronger in the Russia-Asia region than in Europe due to corresponding changes in the $\left[\mathrm{O} / \mathrm{N}_{2}\right]$ ratio. The joint effects of the meridional neutral wind and the seasonal changes of the subsolar point lead to the increase in the extent of TEC winter anomaly at latitude band $15^{\circ}-30^{\circ} \mathrm{N}$. In the southern hemisphere, TEC winter anomaly does not seem to exist in 2002.

The equinoctial asymmetries in the ionosphere and thermosphere are presented using GPS TEC and the $\left[\mathrm{O} / \mathrm{N}_{2}\right]$ ratio, and the strong equinoctial asymmetry observed in ionospheric TEC is contrary to the observed asymmetry in thermospheric composition. The TEC values are stronger in March than in September, but the values of the $\left[\mathrm{O} / \mathrm{N}_{2}\right]$ ratio are stronger in September than in March.

Acknowledgments. The authors would like to thank data centre of IGS and the Crustal Movement Observation Network of China (CMONC) for providing GPS data. Also the authors would like to thank the NASA's GSFC for providing the NRLMSISE00 atmosphere model. Special thanks should be given to Dr. Sue Lynn Choy at the RMIT University for her valuable suggestions and help. This research is supported by the National Science Fund for Distinguished Young Scholars of China (Grant No. 40625013), 863 program (Grant No. 2007AA12Z311), the National Natural Science Foundation of China (Grant No. 40674012 and No. 40890160), Australian Research Council (Grant No. LP0455170 and LP0669259) endorsed to the research teams led by A/Professor Kefei Zhang, and the overseas outstanding Chinese scholar fund of Chinese Academy of Sciences (Grant No. 2005-1-15).

\section{References}

Appleton, E. V., Temperature changes in the higher atmosphere, Nature, 136, 52-53, 1935.

Bailey, G. J., J. F. Vickrey, and W. E. Swartz, Topside ionosphere above Arecibo during summer at sunspot minimum and the influence of an interhemispheric flow of thermal protons, J. Geophys. Res., 87(A9), 7557-7568, 1982.
Balan, N. and G. J. Bailey, Modelling studies of equatorial plasma fountain and equatorial anomaly, Adv. Space Res., 18(3), 107-116, 1996.

Balan, N. and Y. Otsuka, Equatorial asymmetries in the ionosphere and thermosphere observed by the MU radar, J. Geophys. Res., 103(A5), 9481-9495, 1998

Balan, N., G. J. Bailey, R. J. Moffett, Y. Z. Su, and J. E. Titheridge, Modelling studies of the conjungate-hemisphere differences in ionospheric ionization at equatorial anomaly latitudes, J. Atmos. Terr. Phys., 57(3), 279-292, 1995.

Balan, N., G. J. Bailey, M. A. Abdu, K. I. Oyama, P. G. Richards, J. MacDougall, and I. S. Batista, Equatorial plasma fountain and its effects over three locations: Evidence for an additional layer, the $\mathrm{F}_{3}$ layer, $J$. Geophys. Res., 102(A2), 2047-2056, 1997a.

Balan, N., Y. Otsuka, and S. Fukao, New aspects in the annual variation of the ionosphere observed by the MU radar, Geophys. Res. Lett., 24(18), 2287-2290, 1997b.

Ducan, R. A., F-region seasonal and magnetic storm behaviour, J. Atmos. Terr. Phys., 31, 59-70, 1969.

Ennis, A. E., G. J. Bailey, and R. J. Moffett, Vibrational nitrogen concentration in the ionosphere and its dependence on season and solar cycle, Ann. Geophys., 13, 1164-1171, 1995.

Huo, X. L., Y. B. Yuan, J. K. Ou, D. B. Wen, and X. W. Luo, The diurnal variations, semiannual and winter anomalies of the ionospheric TEC based on GPS data in China, Prog. Nat. Sci., 15(1), 56-60, 2005.

Jenkins, B., G. J. Bailey, A. E. Ennis, and R. J. Moffett, The effect of vibrationally excited nitrogen on the low-latitude ionosphere, Ann. Geophys., 15, 1422-1428, 1991.

Jin, S. and J.-U. Park, GPS ionospheric tomography: A comparison with the IRI-2001 model over South Korea, Earth Planets Space, 59(4), 287292, 2007.

Kawamura, S., N. Balan, Y. Otsuka, and S. Fukao, Annual and semiannual variations of the midlatitude ionosphere under low solar activity, $J$. Geophys. Res., 107(A8), 1166, 10.1029/2001JA000267, 2002.

King, G. A. M., The dissociation of oxygen and high level circulation in the atmosphere, J. Atmos. Terr. Phys., 29, 1529-1539, 1964.

Kotake, N., Y. Otsuka, T. Ogawa, T. Tsugawa, and A. Saito, Statistical study of medium-scale traveling ionospheric disturbances observed with the GPS networks in Southern California, Earth Planets Space, 59(2), 95-102, 2007.

Lin, C.-H., J.-Y. Liu, H.-F. Tsai, and C.-Z. Cheng, Variations in the equatorial ionization anomaly peaks in the Western Pacific region during the geomagnetic storms of April 6 and July 15, 2000, Earth Planets Space, 59(5), 401-405, 2007.

Mannucci, A. J., B. D. Wilson, D. N. Yuan, C. H. Ho, and U. J. Lindqwister, A global mapping technique for GPS-derived ionospheric total electron content measurements, Radio Sci., 33(3), 565-601, 1998.

Millward, G. H., H. Rishbeth, T. J. Fuller-Rowell, A. D. Aylward, S. Quegan, and R. J. Moffett, Ionospheric $\mathrm{F}_{2}$ layer seasonal and semiannual variations, J. Geophys. Res., 101(A3), 5149-5156, 1996.

Namgaladze, A. A., A. N. Namgaladze, and M. A. Volkov, Numerical modeling of the thermospheric and ionospheric effects of magnetospheric processes in the cusp region, Ann. Geophys., 14, 1343-1355, 1997.

Pavlov, A. V. and N. M. Pavlova, Cause of the mid-latitude NmF2 winter anomaly at solar maximum, J. Atmos. Terr. Phys., 67, 862-877, 2005.

Picone, M., A. E. Hedin, D. P. Drob, and A. C. Aikin, NRLMSISE-00 empirical model of the atmosphere: Statistical comparisons and scientific issues, J. Geophys. Res., 107(A12), 1468, doi:10.1029/2002JA009430, 2002.

Richards, P. G. and D. G. Torr, A factor of 2 reduction in theoretical F2 peak electron density due to enhanced vibrational excitation of N2 in summer at solar maximum, J. Geophys. Res., 91, 11331-11336, 1986.

Rishbeth, H., How the thermospheric circulation affects the ionospheric F2-layer, J. Atmos. Sol. Terr. Phy., 60, 1385-1402, 1998.

Rishbeth, H. and C. S. G. K. Setty, The F-layer at sunrise, J. Atmos. Terr. Phys., 21, 263-276, 1961.

Rishbeth, H., I. C. F. Müller-Wodarg, L. Zou, T. J. Fuller-Rowell, G. H. Millward, R. J. Moffett, D. W. Idenden, and A. D. Aylward, Annual and semiannual variations in the ionospheric $\mathrm{F}_{2}$-layer: II. Physical discussion, Ann. Geophys., 18, 945-956, 2000.

Schaer, S., Mapping and predicting the earth's ionosphere using the global positioning system, Ph.D. Thesis, Astronomisches Institute of University Bern, Switzerland, 1999.

Shepherd, G. S., Dayside cleft auroral and its ionospheric effects, Rev. Geophys. Space Phys., 12, 2017-2033, 1979.

Su, Y. Z., G. J. Bailey, and K. I. Oyama, Annual and seasonal variations in 
the low-latitude topside ionosphere, Ann. Geophys., 16, 974-985, 1998. Torr, M. R. and D. G. Torr, The seasonal behavior of the $F_{2}$ layer of the ionosphere, J. Atmos. Terr. Phys., 35, 2237-2251, 1973.

Tsai, H., J. Liu, W. Tsai, and C. Liu, Seasonal variations of the ionospheric total electron content in Asia equatorial anomaly regions, J. Geophys. Res., 106(A12), 30363-30369, 2001.

Yuan, Y. B. and J. K. Ou, Preliminary results and analyses of using IGS GPS data to determine global ionospheric TEC, Prog. Nat. Sci., 13(6), 446-450, 2003.

Yuan, Y. B., X. L. Huo, and J. K. Ou, Models and methods for precise determination of ionospheric delay using GPS data, Prog. Nat. Sci., 17(2), 187-196, 2007.

Walk, G. O., J. H. K. Ma, and E. Golton, The equatorial ionospheric anomaly in eletrcon content from solar minimum to solar maximum for South East Asia, Ann. Geophys., 12, 195-209, 1994.

X. L. Huo (e-mail: xingliang.huo@gmail.com), Y. B. Yuan (e-mail: yybgps@asch.whigg.ac.cn), J. K. Ou, K. F. Zhang, and G. J. Bailey 